\title{
分光ミュラー行列偏光計
}

\author{
大 谷幸 利 \\ 宇都宮大学 オプティクス教育研究センター 齿321-8585 栃木県宇都宮市陽東 7丁目 1-2
}

（2014 年 4 月 14 日受付；2014 年 7 月 11 日掲載決定）

\section{Spectroscopic Mueller Matrix Polarimetry}

\begin{abstract}
Yukitoshi OTANI
Center for Optical Research and Education, Utsunomiya University, 7-1-2 Yoto, Ustunomiya, Tochigi 321-8585
\end{abstract}

(Received April 14, 2014 ; Accepted July 11, 2014)

\begin{abstract}
Polarization tool as ellipsometry is a classic but still new technology. It is used in various fields : from materials science, such as the newest nanotechnology and optical function material, to biotechnology in recent years. It has been developing into the new areas, called polarization science and polarization technology. This paper reviews a measurement method for spectroscopic Mueller matrix such as a dual rotating retarder type polarimeter, a liquid crystal phase modulation type polarimeter, and a channeled spectrum polarimeter. In addition, the important analysis is introduced for equipment calibration and a decomposition method from obtained Mueller matrix.
\end{abstract}

KEYWORDS : spectroscopic Mueller matrix, Mueller matrix polarimeter, Stokes parameters, decomposition

\section{1.は じめに}

偏光は古くて新しい技術である。近年，最新のナノテ クノロジー, 光機能性材料などの材料科学から生命工学 まで様々な分野で偏光がキーワードとなり, 一種の偏光 科学とか偏光工学といわれる分野にまで発展している。 一般に, 光のそのものの偏光状態は, 直線偏光, 楕円偏 光や円偏光としてジョーンズベクトルで表される ${ }^{1)}$ 。ま た, 物質の光学特性は, 反射による偏光変化, 複屈折, 二色性や円二色性としてジョーンズ行列で表すことがで きる。しかしながら, 実際には物理量の多様化に伴い, 直線偏光, 円偏光などの完全偏光に加えて, 部分偏光や 非偏光（ランダム偏光）が存在する。これらの偏光状態 は，ストークス・パラメータとして表現できる。また， 光学特性には, 複屈折や二色性のほかに偏光解消が存在 する。これらは，ミュラー行列として取り扱うことがで きる。さらに, これらの偏光状態が混在することも多々 起こっており，その解釈がますます重要になってくる。 反射光の偏光特性をとらえるエリプソメータが有名であ

E-mail : otani@cc.utsunomiya-u.ac.jp
る。一般に, 表面状態の解析には, 楕円率角と楕円化方 位を求めるエリプソメータが用いられている ${ }^{2,3)}$ 。これ により, 薄膜の厚さや屈折率を求めることができる。し かしながら, サンプルの構造による散乱が発生する場 合, 偏光解消が起こる。この場合には, エリプソパラメ ータのみでは不十分である。これに対して，ストーク ス・パラメータやミュラー行列は非偏光まで評価できる ので, 今後の材料評価の高品位化には重要なファクター になると考える。現在では, エリプソメータでミュラー 行列から解析を行っている手法をミュラー行列エリプソ メータと呼んでいる。

Table 1 は, 物質の偏光特性を表すジョーンズ行列と ミュラー行列の偏光自由度を示す。ジョーンズ行列は 2 行 2 列の 4 要素を実数と虚数で表現する 8 自由度であ る。これに対してミュラー行列は 4 行 4 列の 16 自由度 (スカラー量) である。偏光特性は大きく分けて, (1)偏 光の位相変化を表す位相遅れ (retardation), (2)偏光の吸 収（減衰変化）を表す複吸収 (diattenuation), (3)偏光の スクランブルを表す偏光解消（depolarization）に分類す ることができる ${ }^{4)}$ 。さらに, リターダンスは直線複屈折 と円複屈折（旋光）に, ダイアテニュエイションは直線 
Table 1. Freedom of polarization properteis.

\begin{tabular}{|c|c|c|c|c|}
\hline Freedom & $\begin{array}{c}\text { polarization } \\
\text { properites }\end{array}$ & physical properties & \multicolumn{2}{|c|}{ calculation process } \\
\hline 1 & \multirow{2}{*}{ non } & phase (wavefront aberration) & \multirow{6}{*}{$\begin{array}{l}\text { Jones } \\
\text { matrix }\end{array}$} & \multirow{7}{*}{$\begin{array}{c}\text { Mueller } \\
\text { matrix }\end{array}$} \\
\hline 2 & & intensity (transmittance) & & \\
\hline 3,4 & \multirow{2}{*}{ retardance } & $\begin{array}{l}\text { (linear) birefringence } \\
\text { [magnitude, direction }]\end{array}$ & & \\
\hline 5 & & $\begin{array}{c}\text { (circular) birefringence } \\
\text { [circular activity, optical rotation] }\end{array}$ & & \\
\hline 6,7 & \multirow{2}{*}{ diattenuation } & $\begin{array}{l}\text { (linear) diattenuation (dicroism) } \\
\text { [magnitude, direction }\rceil\end{array}$ & & \\
\hline 8 & & $\begin{array}{l}\text { (circular) diattenuation } \\
\text { (circular dicroism) }\end{array}$ & & \\
\hline $9 \sim 16$ & depolarization & depolarization & & \\
\hline
\end{tabular}

複吸収 (二色性) と円複吸収 (円二色性) という偏光特 性で表すことができる。

一般に, ミュラー行列を計測した場合, 位相遅れ, 複 吸収, および偏光解消が混在してしまう。これをデコン ポジション法で分離することで偏光特性のパラメータな ど個々の物理量として求めることが可能となる4)。たと えば, 散乱によって偏光解消している情報から, 偏光特 性パラメー夕を取り出すことも可能である。さらに, 個々の偏光特性は波長依存性を持つため, これらの組み 合わせからなるミュラー行列も波長依存性を持つ。

分光ミュラー行列偏光計で, 一般に用いられているの はAzzam によって提案された二重回転位相子型偏光計 である ${ }^{5)}$ 。さらに, 液晶位相変調器を用いた手法, チャ ンネルドスペクトルミュラー行列偏光計が代表的な手法 である。ここでは, 代表的な分光ミュラー行列偏光計と そのデコンポジションについて紹介する。

\section{2.ストークス・パラメータとミュラー行列}

ここでは，まず，光の偏光状態を表すストークス・パ ラメータと偏光素子の偏光状態を表すミュラー行列につ いて述べる ${ }^{4,6)}$ 。我々が扱う偏光状態の表現にはジョー ンズ行列とストークス・パラメータがある。前者は, 単 色光でかつ完全偏光のみで成り立ち振幅と絶対位相を扱 うことができるが, 後者は, インコヒーレント光で部分 偏光や非偏光を扱うことができる。さらに, ストーク ス・パラメータは振幅ではなく光強度を扱うことができ る。

Fig. 1 に示すように, z 軸方向へ進行する光の偏光状 態を考える。電気界成分を $\mathrm{xy}$ 方向に分け, $E_{x}, E_{y}$ の振 幅を $A_{x}, A_{y}$, それらの初期位相 $\delta_{1} \delta_{2}$ の間の位相差を $\delta$ とする。

ストークス・パラメータは $s_{0}$ から $s_{3}$ の四つの要素で

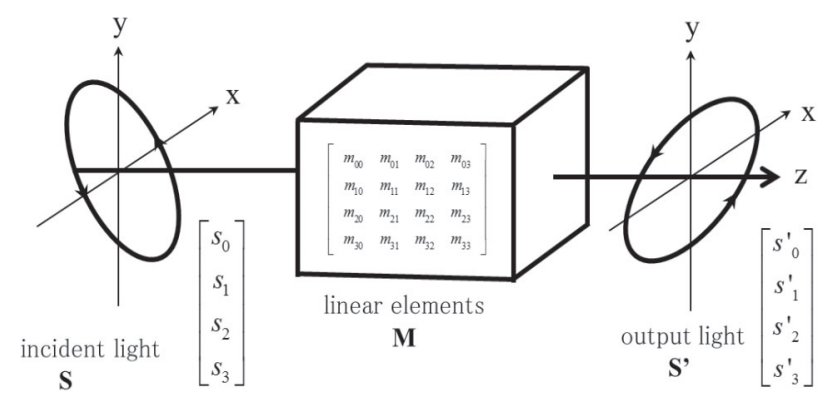

Fig. 1. Relationship states of polarization of input and output beam.

以下のように表すことができる。

$$
\begin{aligned}
& s_{0}=\left\langle E_{x} E_{x}{ }^{*}+E_{y} E_{y}{ }^{*}\right\rangle=A_{x}{ }^{2}+A_{y}{ }^{2} \\
& s_{1}=\left\langle E_{x} E_{x}{ }^{*}-E_{y} E_{y}{ }^{*}\right\rangle=A_{x}{ }^{2}-A_{y}{ }^{2} \\
& s_{2}=\left\langle E_{x}{ }^{*} E_{y}+E_{x} E_{y}{ }^{*}\right\rangle=2 A_{x} A_{y} \cos \delta \\
& \left.s_{3}=i<E_{x}{ }^{*} E_{y}-E_{x} E_{y}{ }^{*}\right\rangle=2 A_{x} A_{y} \sin \delta
\end{aligned}
$$

このストークス・パラメータの各成分は, $s_{0}$ 成分は光 強度, $s_{1}$ 成分は水平直線偏光成分, $s_{2}$ 成分は $45^{\circ}$ 直線偏 光成分， $s_{3}$ 成分は右円偏光成分である。

Fig. 1 に示すような透過, または反射する線形光学素 子を考える。入射光と, 光学素子からの出射光の偏光状 態の変化は, ストークス・パラメータで 1 行 4 列 4 要素 からなる $\mathbf{S}, \mathbf{S}^{\prime}$ で関倸づけられるので,

$$
\begin{aligned}
& \mathbf{S}^{\prime}=\mathbf{M} \cdot \mathbf{S} \\
& {\left[\begin{array}{l}
s^{\prime}{ }_{0} \\
s^{\prime}{ }_{1} \\
s^{\prime}{ }_{2} \\
s^{\prime}{ }_{3}
\end{array}\right]=\left[\begin{array}{llll}
m_{00} & m_{01} & m_{02} & m_{03} \\
m_{10} & m_{11} & m_{12} & m_{13} \\
m_{20} & m_{21} & m_{22} & m_{23} \\
m_{30} & m_{31} & m_{32} & m_{33}
\end{array}\right]\left[\begin{array}{l}
s_{0} \\
s_{1} \\
s_{2} \\
s_{3}
\end{array}\right],}
\end{aligned}
$$

と表される光学素子は 4 行 4 列のマトリックス, つまり ミュラー行列 M で表わすことができる。

入射光が $\mathrm{N}$ 個の光学素子 $\mathrm{M}_{\mathrm{N}}$ を透過する場合, 光検 
出器で検出される光強度は, 各光学素子とストークス・ パラメー夕 $S^{\prime}$ の掛け合わせにより求めることができる。 また, ミュラー行列はすでに光強度を扱っているので要 素 $s_{0}$ 成分が光強度となる。 $\mathrm{N}$ 個の光学素子 $\mathrm{M}_{1} \sim \mathrm{M}_{\mathrm{N}}$ を 光が透過するとき，入出射光のストークス・パラメータ とミュラー行列の関係は

$$
\begin{aligned}
\mathbf{S}^{\prime} & =\mathbf{M}_{\mathrm{N}}\left[\cdots\left[\mathbf{M}_{2} \cdot\left[\mathbf{M}_{1} \cdot \mathbf{S}\right]\right]\right] \\
& =\mathbf{M}_{\mathrm{N}} \cdots \mathbf{M}_{2} \mathbf{M}_{1} \cdot \mathbf{S}
\end{aligned}
$$

となる。

ミュラー行列の 16 個の要素は, 各偏光特性である二 色性 (複吸収), 円二色性 (円複吸収), 複屈折性（直線 リターダンス), 旋光性（円リターダンス）として特定 の要素に現れるので, 次式のように色分けすることがで きる。

$$
\mathbf{M}=\left[\begin{array}{cccc}
m_{00} & m_{01} & m_{02} & m_{03} \\
m_{10} & m_{11} & m_{12} & m_{13} \\
m_{20} & m_{21} & m_{22} & m_{23} \\
m_{30} & m_{31} & m_{32} & m_{33}
\end{array}\right]
$$

ミュラー行列は様々な偏光パラメータが混在したサン プルを評価するのに有効であるが，実際には，求められ たミュラー行列から混在した偏光特性を理解することは 容易でない。実際は, 求まったミュラー行列から混在し た各偏光特性を分離し, 個々の偏光特性を導出する必要 がある。

ミュラー行列 $\mathrm{M}$ は偏光解消性を示す行列 $\mathrm{M}_{\Delta}$, （直 線・円）複屈折成分 (retardance) を示す行列 $\mathrm{M}_{\mathrm{R}}$, およ び，直線・円）複吸収成分（diattenuation）を示す行列 $\mathrm{M}_{\mathrm{D}}$ を用いて，

\section{$\mathbf{M}=\mathbf{M}_{\Delta} \mathbf{M}_{\mathrm{R}} \mathbf{M}_{\mathbf{D}}$}

と偏光分離することができる ${ }^{4,5)}$ 。さらに, これらを直 線複屈折と円複屈折など各偏光パラメータに分離する。

\section{3. 二重回転位相子型分光ミュラー行列偏光計}

Fig. 2 は Azzam により提案された二重回転位相子型ミ ユラー行列偏光計の光学系である7)。光源からの光は偏 光子 $\mathrm{P}$ を経て, サンプル $\mathrm{M}$ の両側に設置された 2 枚の 回転 1/4 波長板 $\mathrm{Q} 1, \mathrm{Q} 2$ を透過後, 検光子 A を通って 検出器で光強度として検出される。2枚の $1 / 4$ 波長板を $1: 5$ の角度比で回転させると, 回転により変調された 光強度は, 入射光と各光学素子のストークス・パラメー タとミュラー行列から,

$$
I=\frac{1}{4} I_{0}\left\{m_{00}+\frac{1}{2} m_{01}+\frac{1}{2} m_{10}+\frac{1}{4} m_{11}+\left(m_{03}+\frac{1}{2} m_{13}\right) \sin 2 \theta\right.
$$

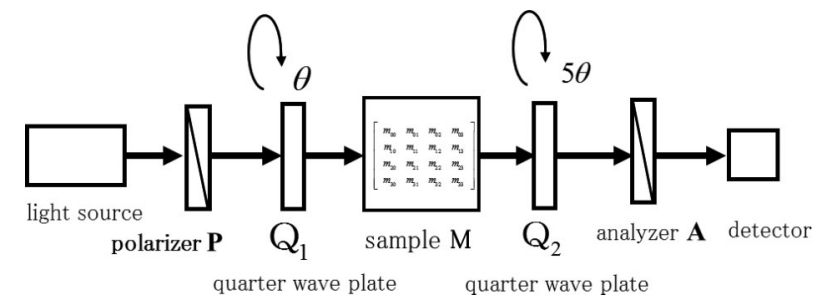

Fig. 2. Dual rotating Mueller matrix polarimeter.

$$
\begin{aligned}
& +\left(\frac{1}{2} m_{01}+\frac{1}{4} m_{11}\right) \cos 4 \theta+\left(\frac{1}{2} m_{02}+\frac{1}{4} m_{12}\right) \sin 4 \theta \\
& -\frac{1}{4} m_{32} \cos 6 \theta-\frac{1}{4} m_{31} \sin 6 \theta-\frac{1}{2} m_{33} \cos 8 \theta \\
& +\left(-m_{30}-\frac{1}{2} m_{31}\right) \sin 10 \theta+\frac{1}{2} m_{33} \cos 12 \theta \\
& +\frac{1}{4} m_{32} \cos 14 \theta-\frac{1}{4} m_{31} \sin 14 \theta+\left(\frac{1}{8} m_{11}+\frac{1}{8} m_{22}\right) \cos 16 \theta \\
& +\left(-\frac{1}{8} m_{12}+\frac{1}{8} m_{21}\right) \sin 16 \theta+\frac{1}{4} m_{23} \cos 18 \theta-\frac{1}{4} m_{13} \sin 18 \theta \\
& +\left(\frac{1}{2} m_{10}+\frac{1}{4} m_{11}\right) \cos 20 \theta+\left(\frac{1}{2} m_{20}+\frac{1}{4} m_{21}\right) \sin 20 \theta \\
& -\frac{1}{4} m_{23} \cos 22 \theta+\frac{1}{4} m_{13} \sin 22 \theta \\
& \left.+\left(\frac{1}{8} m_{11}-\frac{1}{8} m_{22}\right) \cos 24 \theta+\left(\frac{1}{8} m_{12}+\frac{1}{8} m_{21}\right) \sin 24 \theta\right\} \\
& =\frac{1}{4} I_{0}\left[a_{0}\left(m_{i j}\right)+\sum_{n=1}^{12}\left\{a_{n}\left(m_{i j}\right) \cos 2 n \theta+b_{n}\left(m_{i j}\right) \sin 2 n \theta\right\}\right]
\end{aligned}
$$

となる。

ここで, $m_{i j}$ はミュラー行列の各要素, $a_{0}, a_{n}, b_{n}$ は $1 / 4$ 波長板の回転角 $\theta$ に対するフーリエ振幅である。 (ここでは光強度の $n \omega$ 成分の振幅を $a_{n} \cos (n \omega)$ 成分, $b_{n} \sin (n \omega)$ 成分を $a_{n}, b_{n}$ としている。

Fig. 2 において二つの $1 / 4$ 波長板の主軸方位および複 屈折位相差の䛊差は, ミュラー行列の主たる䛊差要因と なる。Chipman, Goldstein の手法は, このキャリブレー ション法として有名である ${ }^{4,8)}$ 。2枚の $1 / 4$ 波長板の複屈 折位相差の誤差および方位誤差を測定サンプルのない状 態で計測したフーリエ級数よりあらかじめ誤差の值を算 出することで, これらの誤差を補正した高精度のミュラ 一行列を求めることができる。

Fig. 3 は, 反射型二重回転位相型偏光計である ${ }^{9)}$ 。光 源にハロゲンランプ, 検出器にグリズムによるライン型 分光器を用いることで分光ミュラー行列計測を求めるこ とができる。また, アーム型のため入射角を鉛直から $30^{\circ}$ から $90^{\circ}$ で稼動できる。入射角 $90^{\circ}$ のとき透過型偏 光計となり, キャリブレーションをすることができる。 
Fig. 4 はワイヤーグリッド偏光子の波長 460〜680 nm における光の分光ミュラー行列である。 $m_{00}$ から $m_{33}$ ま で横軸を波長, 縦軸をミュラー行列の值として \pm 1 とし て 16 個のグラフで表している。サンプルは, 2 色性の 偏光子なので理論值のミュラー行列は左上の四つの要素

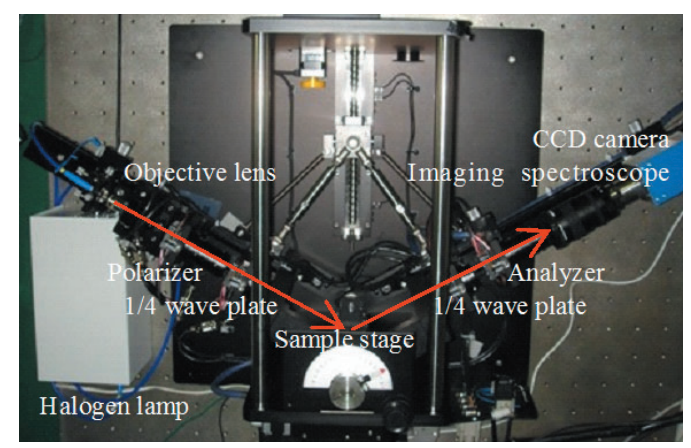

Fig. 3. (color online). Photograph of dual rotating Mueller matrix polarimeter.

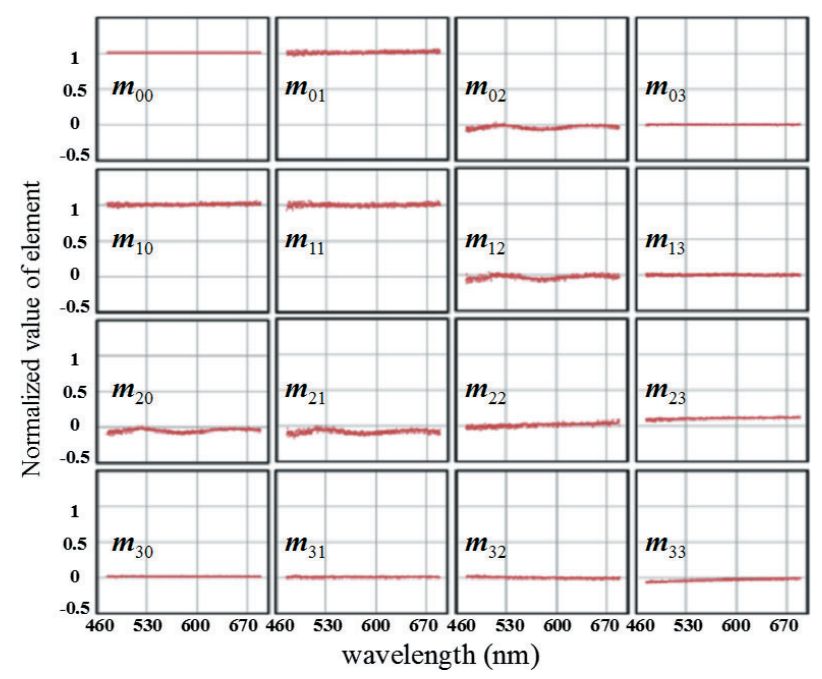

Fig. 4. (color online). Experimental result of spectroscopic Mueller matrix of a wire grid polarizer.
が 1 となりあとは 0 となる。実測值と数値解析值はよく 一致した結果となった。

\section{4. 液晶位相変調素子による分光ミュラー行列 偏光計}

Fig. 5 は液晶位相変調器（LC 変調器）を用いた分光 ミュラー行列偏光計である ${ }^{10)}$. LC 変調器は, 主軸方位 の異なった 2 枚を組み合わせることによって回転位相子 と同じ働きができる。偏光変調器である液晶リターダ LCR1, LCR2 の複屈折位相差 $\delta_{1}, \delta_{2}$ と, サンプル M を 透過した偏光解析器である液晶リターダ LCR3, LCR4 の複屈折位相差 $\delta_{3}, \delta_{4}$ によって位相変調され, 検光子 $\mathrm{A}$ によって光強度として検出される。 LC 偏光変調器と $\mathrm{LC}$ 解析器を $\delta: 5 \delta$ の関係で位相変調したときの, 位相 $\delta$ に対する光強度のフーリエ級数 $a_{0}, a_{n}, b_{n}$ からミュラ 一行列の各要素を求めることができる。ミュラー行列偏 光計の誤差要因は, 液晶リターダ 1〜4 と主軸方位誤差 である。ここでもサンプルのない状態でミュラー行列か ら校正することが可能である。

実際のミュラー行列の各要素の精度検定の結果, 標準 偏差は 0.0008 となった。Fig. 6 は 1/4 波長の位相差フィ ルムを計測した結果である。Fig. 6 (a) はミュラー行列

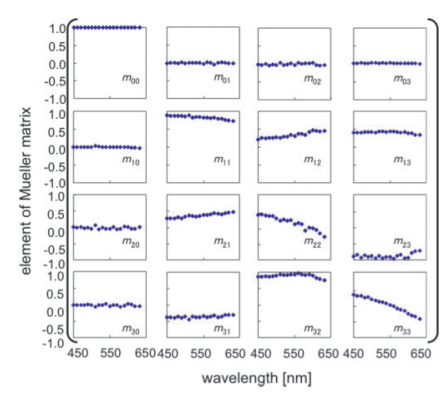

(a) Spectroscopic Mueller matrix

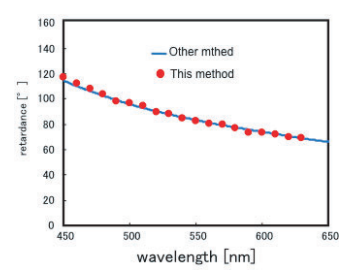

(b) Retardance dispersion
Fig. 6. (color online). Experimental result of a quarter wave film.

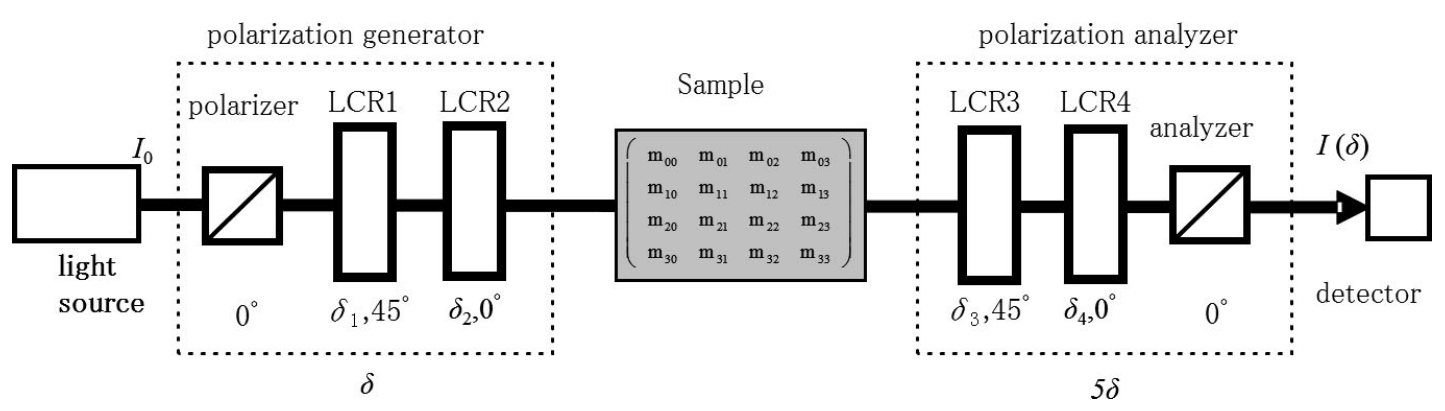

Fig. 5. Spectroscopic Mueller matrix polarimeter by liquid crystal phase modulators. 

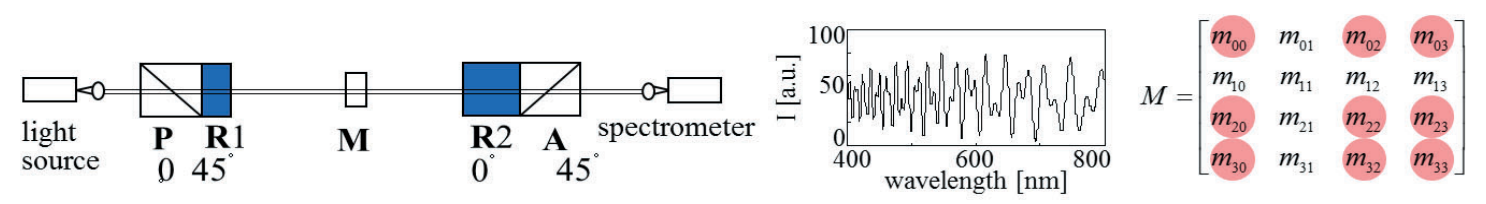

(a) 1 shot : $\left[\begin{array}{llll}0^{\circ} & 45^{\circ} & 0^{\circ} & 45^{\circ}\end{array}\right]$
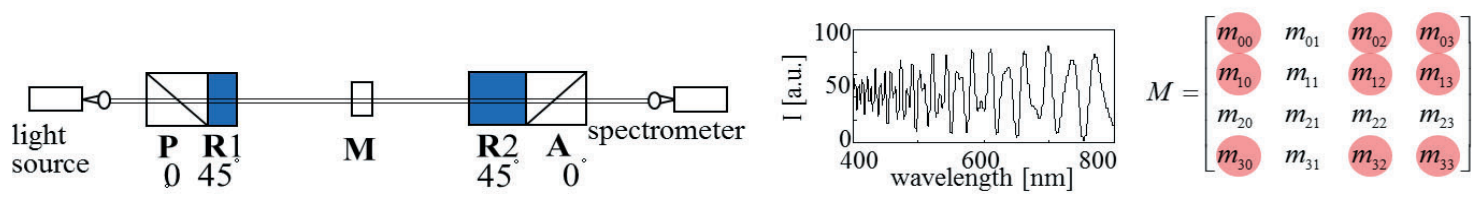

(b) 2 shot : $\left[\begin{array}{llll}0^{\circ} & 45^{\circ} & 45^{\circ} & 0^{\circ}\end{array}\right]$
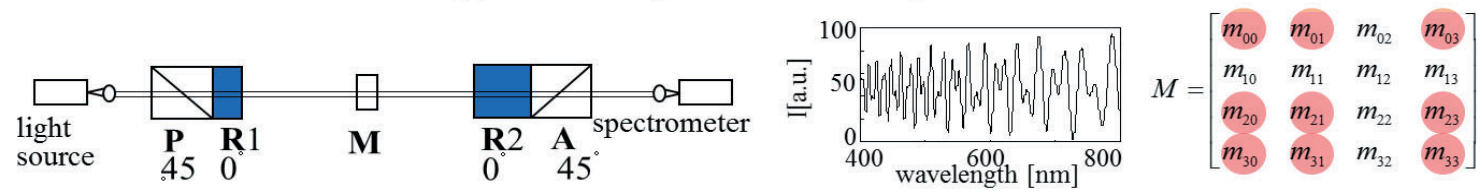

(c) 3 shot : $\left[\begin{array}{llll}45^{\circ} & 0^{\circ} & 0^{\circ} & 45^{\circ}\end{array}\right]$
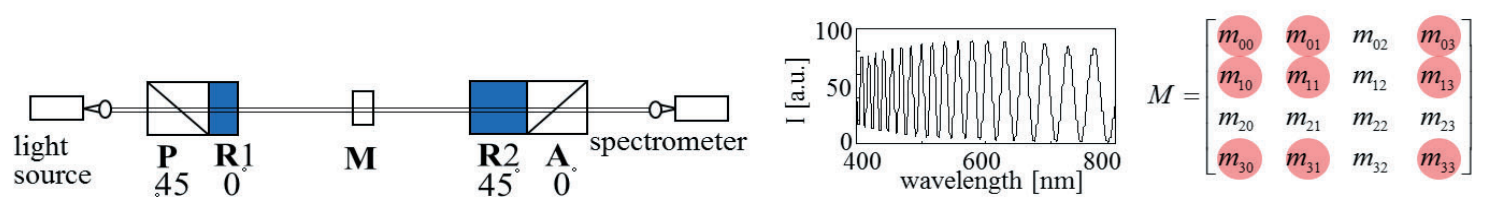

(d) 4 shot : $\left[\begin{array}{llll}45^{\circ} & 0^{\circ} & 45^{\circ} & 0^{\circ}\end{array}\right]$

Fig. 7. (color online). Spectroscopic Mueller matrix polarimeter by channeled spectrum.

を表す。行列の各要素の横軸は, 波長 450〜650 nm に 対するミュラー行列の大きさを \pm 1 で表している。Fig. 6（b）はミュラー行列の結果からデコンポジションして 複屈折位相差の波長特性を表したものである。実線は分 光複屈折計測計による計測結果であり, 丸印が本手法に よる計測結果である。雨者はよく一致した。

\section{5. チャネルドスペクトルによる分光ミュラー 行列偏光計}

偏光子と検光子をクロス・ニコル（または, 平行ニコ ル）に設置し，その間にサンプルを扱入する。ここに白 色照明することで波長によって位相差が異なって発生す る。ここで観察できる干涉色がチャネルドスペクトルで ある ${ }^{11 \sim 13)}$ 。チャネルドスペクトルの光強度は, 波数 $k$ に 対して分光強度が正弦状に変化する。ただし, サンプル の複屈折位相差が波長依存性をもつため空間周波数は一 定にならない。そこで, 波長依存性の外部の位相子によ ってキャリア周波数を与える。この空間周波数の振幅と 位相を利用することで部分ミュラー行列を求めることが できる。Fig. 7 は, サンプルを偏光子 P, 位相子 R1 の 偏光変調器と位相子 $\mathrm{R} 2$, 検光子 A の偏光解析器の関係 を示す。ここで, Fig. 7 (a)〜 (d) は, 各光学素子の角 度を変化させたときのチャネルドスペクトルである, 位
相子 R1 と R2 の位相差を高次でかつ波長の整数倍にし ておくとチャネルドスペクトルは, 位相差の和差の空間 周波数の混合されたものとなる。したがって, それぞれ のショットからはミュラー行例 16 個の要素のうち図中 の丸で囲まれた 9 個, つまり, 部分ミュラー行列が求ま る。完全なミュラー行列を求めるためには, リターダお よび偏光子の主軸方位を変えた四つのショットから求め ることができる ${ }^{14)}$ これによって, 最低限四つの組み合 わせで分光完全ミュラー行列が求められる。Fig. 8 は, Fig. 7 の光学系で液晶用位相差フィルム（1/4 波長板 $)$ の分光ミュラー行列を計測した結果である。これから， 4 ショットで分光ミュラー行列が計測可能であることが わかる。

さらに, 外部からの位相子のキャリア周波数を重複し ないように設定, サンプルの前後二つずつのキャリアリ ターダにより, スナップショット分光ミュラー行列偏光 計測が可能となる ${ }^{15)}$ これらのスペクトルの組み合わせ は, Fig. 7 の場合に比べてかなり複雑になる。1, 2, 5, 10 倍のリターダを用意して, 18 次まで得られるチャン ネルドスペクトルの0 次までのフーリエ級数を使って 16 個すべてのミュラー行列を求めることができる。さ らに, ホログラムと 2 次元 CCD カメラを使った 2 次元 分光カメラと組み合わせることでスナップショット 2 次 


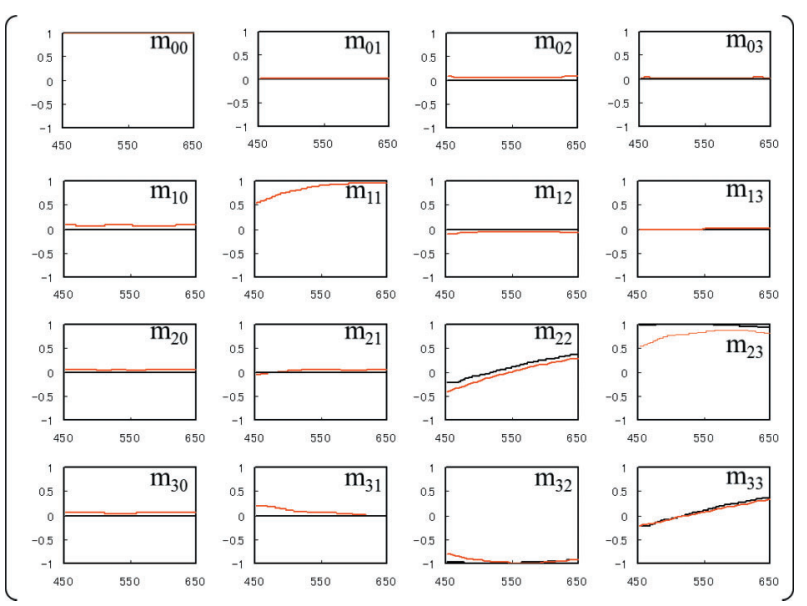

Fig. 8. (color online). Experimental result of spectroscopic Mueller matrix of a quarter wave retardance film.

元分光ミュラー行列偏光計が可能となる。

\section{6. を と}

光学技術の高度化とともに, 偏光の問題について盛ん に議論されている。ストークス・パラメータとミュラー 行列は，インコヒーレント光で部分偏光や非偏光で扱う ことができるため，今後ますますの発展が期待できる。 分光ミュラー行列計測法は, いくつか代表的な手法が提 案され害用化もされている。今回紹介しきれなかった が, 光弾性変調器を用いた手法は高精度化が期待でき る。一般に, 偏光素子は製造や波長依存性などの要因で 理論どおりにならないので, キャリブレーションが必要 である。また，計測されたミュラー行列は偏光分離によ って, 必要な偏光成分等にデコンポジションする必要が
ある。これらの過程を経て, 複屈折, 旋光性, 二色性, 円二色性や偏光解消に偏光分離することができる。点計 測による手法がすでに製品化されて成功しているのに対 して, 2 次元分光ミュラー行列測定はいまだ有望な装置 がない。2 次元化においては空間分解能をどうするのか などまだまだ解決されなければならい課題がある。

今後, 分光ミュラー行列計測がさらに技術的に発展し ていくことが期待される。

\section{文献}

1) R.C. Jones : J. Opt. Soc. Am. 31, 488 (1941).

2) R.M.A. Azzam and N.M. Bashara: "Ellipsometry and Polarized Light” (North-Holland, 1987).

3) 藤原裕之: “分光エリプソメトリー” (丸善, 2003).

4) D. Goldstein : "Polarized light 2nd Ed." (Marcel Dekker, 2003).

5) S.Y. Lu and R.A. Chipman : J. Opt. Soc. Am. A 13, 1106 (1996).

6) P.S. Theocaris and E.E. Gdoutos: "Matrix theory of photoelasticity" (Springer, 1979).

7) R.M.A. Azzam : Opt. Lett. 2, 148 (1978).

8) D. Goldstein and R. Chipman : J. Opt. Soc. Am. 7, 693 (1990).

9) Y. Otani, T. Kuwagaito and Y. Mizutani : Proc. SPIE 7063, 70630Y (2008).

10) Y. Otani and M. Chujo : Proc. SPIE 7461, 7461Q (2009).

11) J.W. Ellis and L. Glatt : J. Opt. Soc. Am. 40, 141 (1950).

12) H.G. Jerrard : J. Opt. Soc. Am. 42, 159 (1952).

13) K. Oka and T. Kato : Opt. Lett. 24, 1475 (1999).

14) Y. Otani, T. Wakayama and K. Oka : Opt. Commun. 281, 5725 (2008).

15) N. Hagen, K. Oka and E.L. Dereniak : Opt. Lett. 32, 2100 (2007). 